\title{
Morphology and histology of the male reproductive system of Collaria oleo- sa (Distant, 1883) (Heteroptera: Miridae)
}

Mayra Vélez ${ }^{1,2}$, Glenda Dias ${ }^{3}$, Irina Morales ${ }^{4}$, Raul N. C. Guedes², José Lino-Neto ${ }^{3}$

DOI. 10.21931/RB/2020.05.02.7

\begin{abstract}
Collaria oleosa (Distant, 1883) is a phytophagous bug often observed causing injuries in wheat, barley, and oat crops, besides grass pastures. The male reproductive system of $C$. oleosa has been studied anatomically and histologically. It consists of a pair of testes, each one with two follicles, one pair of seminal vesicles, two pairs of external accessory glands, and an ejaculatory bulb. The testicular follicles exhibit cysts with spermatogonia, spermatocytes, spermatids, and spermatozoa bundles. The testes are connected to the seminal vesicles by the vas deferens. The seminal vesicles are connected to the ejaculatory bulb and are bound by the accessory glands. In mirids belonging to the Stenodemini tribe, the general morphology of the male reproductive system is similar. However, two follicles per testis may be characteristic of the genus Collaria. The anatomy and histology of the male reproductive system in $C$. oleosa provides new information and also contributes to the understanding of the systematics of Stenodemini as well as the Miridae family in general.
\end{abstract}

Key words: Collaria oleosa, internal morphology, grass-feeding, plant bugs, Stenodemini.

\section{Introduction}

Miridae is the largest family of Heteroptera (Hemiptera) with 11,139 species described, distributed in eight subfamilies: Bryocorinae, Cylapinae, Deraeocorinae, Isometopinae, Mirinae, Orthotylinae, Phylinae, Psallopinae, and 39 tribes $^{6,27}$. The mirids exhibit a cosmopolitan distribution, occurring in all biogeographic regions of the planet ${ }^{6,30}$. The genus Collaria (Provancher 1872), belongs to the Stenodemini (Mirinae) tribe with 15 recognized species ${ }^{17}$. Among these species, Collaria oleosa (Distant, 1883) (Fig. 1) has a significant impact, because it is considered as a potential pest in wheat, barley, oats crops, grass pastures and other plants belonging to Poaceae family 8,16.

The plant bug C. oleosa presents economic importance due to the damages that produce when sucks the sap of plants. The youngest leaves attacked by $\mathrm{C}$. oleosa can partially or dry out, delaying the growth, reducing yield and nutritional value of the crops and grasses palatability 1,5,16. Even though the world distribution, host plants, and injuries of this pest is well known, the morphology and histology of the reproductive system have not been studied before.

Studies of Morales et al. ${ }^{17}$ suggest the importance of the reproductive system to identify the species of Collaria genus. The external male genitalia of $C$. oleosa exhibits an outstretched pygophore with a discreet spherical apex, U-shaped left paramere, an almost aligned dorsal margin of the basal sensory lobe, a convex ventral margin, and an aligned right paramere. The endosome has two sclerites, with an expanded lobe that further reaches the secondary gonophores, surrounded with micro-hair fixed on the integument and a distal sclerite, $\mathrm{C}$-shaped with spines. Although this study provides data of the genitalia of $C$. oleosa, detailed information on the male reproductive system of $C$. oleosa is still needed.

Therefore, the purpose of this study is to describe the morphological and histological structures of the male reproductive system of $C$. oleosa, besides, detailed photography of histological sections was included. This contribution will be essential to understand the evolutionary history and morphology of the Miridae family in the Neotropical region and revel characters that can also allow the understanding and the study of

1 Facultad de Ciencias Agrarias, Universidad Técnica Estatal de Quevedo, Quevedo, Los Rios, Ecuador.

2 Departamento de Entomologia, Universidade Federal de Viçosa, Viçosa, Minas Gerais, Brazil.

${ }^{3}$ Departamento de Biologia Geral, Universidade Federal de Viçosa, Viçosa, Minas Gerais, Brazil.

${ }^{4}$ Universidad Pedagógica y Tecnológica de Colombia, Tunja, BY, Colombia.

Corresponding author: mvelez@uteq.edu.ec

Phylogeny, Taxonomy, physiological and behavioral aspects, as well as methods of controlling this pest.

\section{Materials and methods}

Fifteen sexually mature males of $C$. oleosa were collected in the campus of the Federal University of Viçosa, in Viçosa $\left(20^{\circ}\right.$ $45^{\prime} 14^{\prime \prime} \mathrm{S}, 42^{\circ} 52^{\prime}$ 55" W $648 \mathrm{~m}$ ), state of Minas Gerais, Brazil, in the pastures of Bermuda grass (Cynodon sp. (Poaceae)).

\section{Reproductive system morphology}

Adult males were cryoanesthetized and the reproductive system was dissected in $0.1 \mathrm{M}$ sodium phosphate buffer at $\mathrm{pH}$ 7.2. After dissection, it was photographed with a stereoscopic microscope (Discovery V-20 Zeiss) coupled with an AxioCam MRc Zeiss camera (Zeiss, Goettingen, Germany). Length measurements of the structures were made with the software Image Pro-Plus version 4.5 (Media Cybernetics Inc., MD, USA).

\section{Histological analysis}

To obtain the histological sections, reproductive structures were fixed for twenty-four hours in 2.5\% glutaraldehyde solution in $0.1 \mathrm{M}$ phosphate buffer. The material was washed for two hours in the same phosphate buffer, post-fixed in 1\% osmium tetroxide for two hours, and dehydrated in a series of ethanol solutions (30\%, 50\%, 70\%, 90\%, 100\%). Reproductive structures were embedded in a mixture of historesin (Leica Historesin) and alcohol in a proportion of 1:1 and then immersed in pure historesin. Semithin sections ( $0.5 \mu \mathrm{m}$ thick) were obtained using a microtome Leica RM 2155 with a glass knife, after that, they were transferred to histological slides, stained with Harris hematoxylin, eosin, toluidine blue and washed in running water for one minute. The observations and photographs were made using an Olympus BX-60 microscope. All the measurements were obtained with the software Image ProPlus, version 4.5 


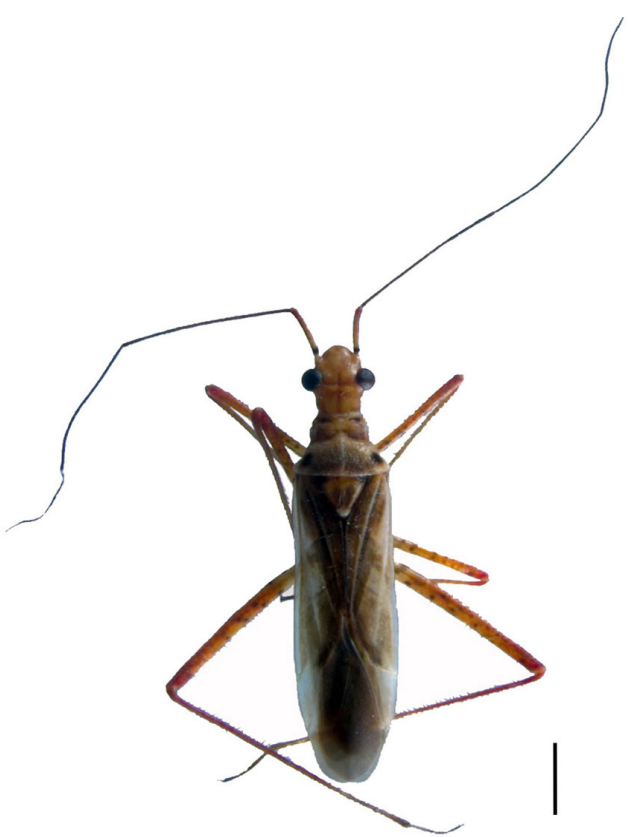

Figure 1. Collaria oleosa male (dorsal view). Scale $1 \mathrm{~mm}$

\section{Results}

\section{Male reproductive system}

The male reproductive system of the $C$. oleosa consists of a pair of testes, each one with two follicles. Each testis opens into a long vas deferens, which has the posterior extremity dilated, forming the seminal vesicle where the sperms are stored until mating. The seminal vesicles connect to the ejaculatory bulb, which is balloon-shaped ( $0.2 \mathrm{~mm}$ in diameter) and bounded to the accessory glands (Fig. 2A-D).
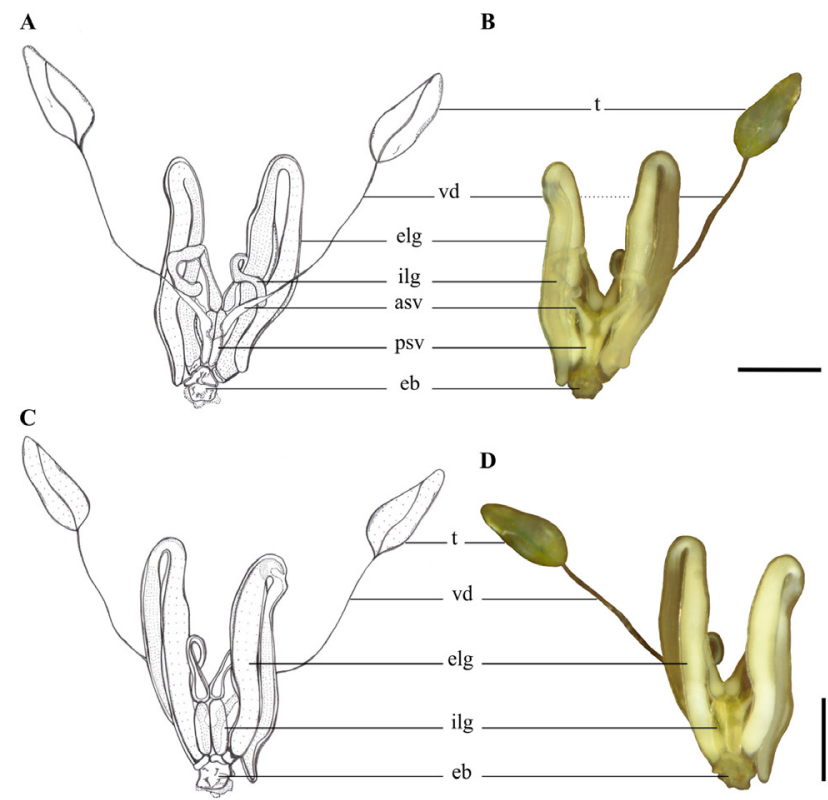

Figure 2. Overview of male reproductive system of Collaria oleosa. A-B, Diagram and light microscopy $(\times 40)$ (dorsal view); C-D, Diagram and light microscopy (× 40) (ventral view); testes (t); vas deferens (vd); anterior seminal vesicle (asv); posterior seminal vesicle (psv); external lateral gland (elg); internal lateral gland (ilg); ejaculatory bulb (eb). Scale, $0,5 \mathrm{~mm}$

\section{Morphology and Histology}

The testes are elongated $(-0.68 \mathrm{~mm}$ in length) $\times 0.26 \mathrm{~mm}$ in width). Each testis consists of two follicles and is surrounded by a testicular capsule with green pigmentation (Fig. 2B and D). The images obtained from histological sections show that the testes of $C$. oleosa are surrounded by a peritoneal membrane, and cysts have been found inside the follicles, from the apex to the base, with spermatogonia, spermatocytes, spermatids, and spermatozoa (Fig. 3A). The spermatogonia are located at the apical region of the follicle, and the cysts with spermatocytes and spermatids are distributed along the follicle (Fig. 3B and C). Subsequently, cysts with spermatozoa were found in the region posterior to the periphery of the follicle (Fig. 3D).

The vasa deferentia are elongated ( $0.96 \mathrm{~mm}$ in length) and form the seminal vesicles. These are divided by an asymmetric constriction in the anterior and posterior regions. The last one opens into the ejaculatory bulb. The vasa deferentia, especially in the vesicular region, exhibit a pearly white color due to the presence of spermatozoa (Fig. 2B and D). Histological analyses show that the seminal vesicles are surrounded by a single layer of epithelial cells. External to the epithelium is observed a well-developed muscle layer. The light of vesicular seminal is entirely filled by free spermatozoa, therefore, not disposed of in bundles (Fig. 4D).

The pair of external accessory glands are elongated with distinguishable ascending and descending arms, of a milky color. The internal accessory glands are shorter and are distinctly divided into two regions, the anterior and posterior regions. The anterior part is elongated and has the shape of a pear with a slight constriction that separates the posterior region. In essence, this last one is translucent, with a cylindrical shape (Fig. $2 \mathrm{~B}$ and $\mathrm{D})$. The walls of both gland types are lined by a single layer of columnar epithelium with at least two different cell types and externally enveloped by a thin muscle layer (Fig. $4 \mathrm{~A}-\mathrm{C}$ ). The lumen of the external accessory gland has its secretion arranged inside of the spherical structures, whereas, in the internal accessory gland, the lumen has granular and irregular secretion (Fig. 4A-C).

\section{Discussion}

Some features of the male reproductive system of $C$. oleosa, such as, the elongated vasa deferentia, position of the seminal vesicles, presence of an ejaculatory bulb and accessory glands, resemble the other species of Stenodemini ${ }^{18,19}$, however, among them there are variations, and they differ from other species usually in the number of testicular follicles.

In the Stenodemini tribe the modal number of testicular follicles is seven, however, it is possible to find species with three, (Myrmecoris gracilis, Notostira elongata, N. errática, Stenodema (Brachystira) calcarata), six (Dolichomiris linearis, Stenodema (Stenodema) laevigata, S. (S.) holsata), or eight (Leptopterna dolabrata; L. ferrugata) testicular follicles 2,14,19. Our study showed that C. oleosa exhibited only two follicles, as found by Akingbohungbe ${ }^{2}$ in Collaria meilleurii, the presence of two follicles may be characteristic of the genus, however, studies on more species of Collaria in different regions where they are usually found (e.g. Neartic, Neotropical and Afrotropical regions) are still necessary.

On the other hand, the number of follicles is an important characteristic that can be used to evaluate the age of the individual genus or species, such us, taxa with a more significant number of follicles are believed to be older than others with a smaller quantity. According to Akingbohungbe and Wheeler ${ }^{2,30}$, 
Stenodema holsata, and Stenotus rubrovittatus ${ }^{3,4,11,9,21 ;}$; although, in C. oleosa, it never has been reported. Further investigations are necessary to confirm this statement.

The analysis of the male reproductive system in C. oleosa shows that there are similar characteristics among other species that belong to the Stenodemini tribe, and the main difference is in the number of testicular follicles. Nevertheless, additional studies on the species of this tribe and genus are necessary. Furthermore, the obtained results provide new information and also contribute to the knowledge of the male reproductive biology of Miridae. Some of the characteristics revealed may be helpful for future studies, in their taxonomy, phylogeny, reproductive physiology, and behavior, which have not yet been fully explored.

\section{Conclusions}

The C. oleosa male reproductive system consists of a pair of testes; each teste showed two follicles, one pair of seminal vesicles, two pairs of external accessory glands, and an ejaculatory bulb. The histological analysis showed that the testicular follicles have cysts with spermatogonia, spermatocytes, spermatids, and spermatozoa bundles. The presence of two follicles per testis on C. oleosa may be characteristic of the genus, however studies on more species of Collaria are still necessary. Morphological and histological analysis provides basic information about the male reproductive system of $C$. oleosa. These findings reveal the presence of characters that may contribute to future studies on the taxonomy and phylogeny of the Stenodemini tribe as well as the Miridae family, also could provide information to understand the biology of $C$. oleosa to search methods of controlling this pest.

\section{Acknowledgments}

This research was supported by the Brazilian agency, Conselho Nacional de Desenvolvimento Cientifico e Tecnológico (CNPq). The authors would like to thank Heloisa Pinheiro (Universidade Federal de Sergipe, São Cristóvão, Sergipe, Brazil) for her assistance in the collection of the material, and Karen Salazar (Departamento de Biologia Geral, Universidade Federal de Viçosa, Viçosa, Minas Gerais, Brazil) for her help in the histological analyses.

\section{Bibliographic references}

1. Auad, A., Pimienta, D., Silva, D., Monteiro, P., Resende, T. 2011. Collaria oleosa (Hemiptera: Miridae) on Brachiaria ruziziensis and Penissetum purpureum (Poaceae): Characterization of injury and biological aspects. Rev. Colomb. Entomol. 37, 244-248.

2. Akingbohungbe, A.E., 1983. Variation in testis follicle number in the Miridae (Hemiptera, Heteroptera) and its relationship to the higher classification of the family. Ann. Entomol. Soc. Am. 76, 37-43.

3. Brent, C.S., 2010. Reproductive refractoriness in the western tarnished plant bug, Lygus hesperus. Ann. Entomol. Soc. Am. 102, 300-306.

4. Carayon, J., 1984. Faits remarquables accompagnant l'insemination chez certains Heteroptères Miridae. Bull. Soc. Entomol. Fr. 89, 982-998.

5. Carlesii, L., Corseuil, E., Salvador, J. 1999. Aspectos Biológicos e Morfométricos de Collaria scenica (Stal) (Hemiptera: Miridae) em Trigo. An. Soc. Entomol. Brasil. 28, 65-73.

6. Cassis, G., Schuh, R., 2012. Systematics, Biodiversity, Biogeography, and Host Associations of the Miridae (Insecta: Hemiptera: Heteroptera: Cimicomorpha). Annu. Rev. Entomol. 57, 377-404.

7. Chapman, R.F., 1998. The Insects: Structure and Function. 4th edition. Cambridge Univ. Press, Cambridge.
8. Da Silva, D., Alves, R., Ferreira, P., Camargo, A., 1994. Collaria oleosa (Distant, 1883) (Heteroptera: Miridae) uma praga potencial na cultura do trigo na região dos Cerrados. Pesq. Agropec. Bra. 29, 2007-2012.

9. Davis N.T., 1956. The morphology and functional anatomy of the male and female reproductive systems of Cimex lectularius $L$. (Heteroptera, Cimicidae). Ann. Entomol. Soc. Am. 49, 466-93.

10. Freitas, S.P.C., Gonçalves, T.C.M., Serrão, J.E., Santos-Mallet, J.R., 2007. Fine structure of the male accessory glands of Triatoma rubrofasciata (Hemiptera: Triatominae) Microsc. Res. Tech. 70, 355-360.

11. Groot, A.T., Van Der Wal, E., Schuurman, A., Visser, J.H., Blommers, L.H.M., Van Beek, T.A., 1998. Copulation behavior of Lygocoris pabulinus under laboratory conditions. Entomol. Exp. Appl. 88, 219-228.

12. Kubli, E., 2003. Sex-peptides: Seminal peptides of the Drosophila male. Cell. Mol. Life Sci. 60, 1689-1704.

13. Leopold, R.A., 1976. The role of male accessory glands in insect reproduction. Annu. Rev. Entomol. 21, 199-221.

14. Leston, D., 1961. Testis follicle number and the higher systematics of Miridae (Hemiptera: Heteroptera). Proc. Zool. Soc. London. 137, 89-106.

15. Masner, P., 1965. The structure, function and the imaginal development of the male inner reproductive organs of Adelphocoris lineolatus (Goeze) (Heteroptera: Miridae). Acta Entomol. Bohemoslov. 62, 254-276.

16. Menezes, M., 1990. Collaria oleosa (Distant, 1883) (Hemiptera: Miridae), nova praga de gramíneas forrageiras no sudeste de Bahia, Brasil. Agrotrópica 2, 113-118.

17. Morales I., Ferreira P.S.F., Forero D., 2016. Taxonomic revision of Collaria Provancher, 1872 (Hemiptera: Miridae) with the description of a new species from the Afrotropical region. Zootaxa 4138, 201-246.

18. Mróz, E., 2007. Anatomical and molecular studies of Stenodema LAPORTE genus (Heteroptera: Miridae). Genus, Supplement.14, 77-81.

19. Mróz, E., Wojciechowski, W., 2011. The systematic position the tribe Stenodemini (Heteroptera: Cimicomorpha: Miridae: Mirinae) in the light of the male internal reproductive system. J. Nat. Hist. 45, 1563-1588.

20. Mróz, E., 2012. The structure of the male reproductive system of the genus Psallus FIEBER (Hemiptera: Heteroptera: Miridae). Pol. Pismo Entomol. 81, 3-10.

21. Oku K., Kitsunezuka, K., 2011. Effects of male mating interval on spermatophore formation, transfer, and subsequent female receptivity and fecundity in the sorghum plant bug, Stenotus rubrovittatus. Entomol. Exp. App. 140, 134-138.

22. Özyurt N., Candan S., Suludere Z., 2013a. The morphology and histology of the male reproductive system in Dolycoris baccarum Linnaeus 1758 (Heteroptera: Pentatomidae) - Light and scanning electron microscope studies. Micron 44, 101-106.

23. Özyurt, N. Candan, S. Suludere, Z. Amutkan, D., 2013b. Morphology and histology of the reproductive system in Graphosoma lineatum (Heteroptera: Pentatomidae) based on optical and scanning electron microscopy. J. Entomol. Zool. Stud. 1, 40-46.

24. Özyurt, N. Candan, S., Suludere, Z., 2014. The morphology and histology of the male reproductive system in Apodiphus amygdali (Germar, 1817) (Hemiptera: Heteroptera: Pentatomidae) Life Excit. Biol. 2, 31-41.

25. Pendergrast, J.G., 1957. Studies on the reproductive organs of the Heteroptera with a consideration of their bearing on classification. Trans. R. Entomol. Soc. Lond. 109, 1-63.

26. Pires, E.M., Ferreira P.S.F., Guedes, R.N.C., Serrão, J.E., 2007. Morphology of the Phytophagous Bug Platyscytus decempunctatus (Carvalho) (Heteroptera: Miridae) Neotrop. Entomol. 36, 510-513.

27. Schuh, R.T., 2002-2013. On-line Systematic Catalog of Plant Bugs (Insecta: Heteroptera: Miridae). http://research.amnh.org/pbi/catalog/"

28. Spurgeon, D.W., Brent, C.S., 2010. Morphological Characters of Diapause in Lygus hesperus Knight (Hemiptera: Miridae). J. Entomol. Sci. 45,303-316.

29. Uceli, L.F., Pirovani, V.D., Vicente, N.M.F., Pikart, T.G., Ferreira, P.S.F., Serrão, J.E., 2011. Morphology of the reproductive and digestive tracts of Adparaproba gabrieli (Heteroptera: Miridae). Int. J. Trop. Insect Sci. 31, 219-224.

30. Wheeler A.G. Jr., 2001. Biology of the Plant Bugs (Hemiptera: Miridae). Pests, Predators, Opportunists. Comstock Publishing Associates. Cornell Univ. Press, Ithaca, New York.

Received: 28 March 2020

Accepted: 9 April 2020 